This item was submitted to Loughborough's Research Repository by the author.

Items in Figshare are protected by copyright, with all rights reserved, unless otherwise indicated.

\title{
Designing through craft practice: A woven textile approach for footwear
}

PLEASE CITE THE PUBLISHED VERSION

https://doi.org/10.1386/crre.10.1.41_1

PUBLISHER

(C) Intellect Ltd

VERSION

AM (Accepted Manuscript)

PUBLISHER STATEMENT

This paper was accepted for publication in the journal Craft Research and the definitive published version is available at https://doi.org/10.1386/crre.10.1.41_1.

\section{LICENCE}

CC BY-NC-ND 4.0

\section{REPOSITORY RECORD}

Pinski, Jenny, Faith Kane, and Mark Evans. 2019. "Designing Through Craft Practice: A Woven Textile Approach for Footwear". figshare. https://hdl.handle.net/2134/36736. 


\title{
Designing Through Craft Practice: A Woven Textile Approach for Footwear
}

\author{
Jenny Pinski ${ }^{1}$, Faith Kane ${ }^{2}$ and Mark Evans ${ }^{1}$ \\ 1. Loughborough University, UK \\ 2. Massey University, NZ
}

\begin{abstract}
Commercial sandals are typically designed in a two-dimensional (2D) format with materials being applied during product development. In contrast, woven textile practitioners frequently utilize hands-on interaction with materials to produce design ideas through a craft-based approach. Hands-on making has been associated with a number of benefits including, but not limited to, knowledge generation and the potential for innovation. This article reports on practice-led research consisting of a sandal design project that integrates craft-based woven textile practice. Action research was used to develop the approach and evaluate the creative potential and practical considerations at different stages of the design process. Ultimately, this research determines where and how craft-based woven textile practice may be integrated into commercial footwear design and identifies the associated creative design potential. Qualitative data was recorded by written and visual means of documentation and analyzed using coding and clustering. The findings indicate that there is novel creative potential associated with the integration of a craft-based woven textile approach to sandal design and that it may be integrated to varying degrees at all stages of the design process. Benefits include opportunities for innovation, generation of in-depth knowledge, control, and immediacy in decision-making. Key challenges were noted in time and cost inefficiencies. The ability to consider material and product design in parallel ensured a considered relationship between the two. This led to benefits in the final designs that included the production of zero-waste, stitch free constructions. This research contributes empirical evidence and findings in relation to theoretical concerns in the area of craft practice as a vehicle for design innovation.
\end{abstract}

\author{
Keywords: \\ Woven textiles; \\ footwear; \\ craft-based design; \\ practice-led research; \\ design process; \\ material-led design
}

\section{Introduction}

Woven textile design typically relies on making as a method of generating and realizing design ideas, whereas footwear designers more commonly utilize two-dimensional (2D) approaches such as digital and hand drawing using. Lawson (1997: 22-23) describes a shift to designers producing drawings as opposed to engaging in craft practice during the industrial revolution due to the time efficient nature of the method. Hands-on interaction through making generates intimate and experiential knowledge of materials and construction (Philpott 2012: 69; Sennett 2009: 160). In the context of this study, a 'craft-based woven textile approach' relates to the use of hand weaving to design and construct textiles along with its associated activities, such as the planning and research that facilitates the use of hand weaving. This article reports on action research that utilized the approach as a method for sandal design and development. 
This research is positioned within the commercial 'ready-to-wear' footwear market where novel, innovative design and quality are key concerns and cost it is a consideration but not a driving factor. Additionally, at the level of the market designs are produced on a large scale, thereby making them accessible to a wide customer base (Verdu-Jover et al. 2008: 1881). The research questions for the study were: is there creative potential associated with the application of a craft-based woven textile approach to commercial sandal design; what are the strengths and weaknesses at different stages of the design process; and how can craft-based woven textile practice be integrated effectively within commercial sandal design?

The strengths and weaknesses associated with the integration of woven textile practice into sandal design are discussed and comparisons drawn between this and conventional methods. Categorized according to whether they are 2D, three-dimensional (3D) and digital, nondigital or a digital/non-digital hybrid, the roles associated with these approaches to design are presented. Analysis was undertaken in relation to a structure of design process stages. Whilst designing is approached in a variety of ways (Lawson 1997: 37-38), the identification of an underlying structure can aid the management of a process that is inherently uncertain and open-ended (Tovey 1997: 13; Goel, 1995) and, in this case, it aided its analysis.

The article presents a literature review that focuses on two key design stages: 'idea generation' and 'design development'. This facilitates a comparison in the use of different approaches at the explorative (idea generation) and practical (design development) phases. The methods used in the practice-led study are then presented and the findings discussed. Finally, a suggested model for an integrated sandal and craft-based woven textile design process is presented. In the discussion, a position is stated in relation to where and how a craft-based woven textile approach could be integrated in relation to the viability and potential for design innovation.

The findings are relevant to the design and craft industries, proposing an outlet for craft practitioners inline with a model for their employment within other creative industries (Trends Business Research 2014: 5). This alternative to a conventional approach may deliver design innovation in footwear, enhancing competitive advantage and subsequently, the creative economy. They are relevant to academia within three distinct areas of design research, woven textiles, footwear and craft-based design. In footwear, current research commonly focuses on efficiency (Antemie et al. 2012; Joneja and Kit 2013; Liao and Jiang 2008; Maurtua et al. 2012) and/or function and performance (Davidson 2012; Head and Porter 2011; Sterzing et al. 2013; Vinet and Caine 2011) and is commonly conducted within the sciences and engineering. In contrast, this research contributes a creative perspective. Additionally, much existing research surrounds the development of digital design processes, however, the impact of limiting materiality is generally not considered. More commonly than in footwear, woven textile design research is conducted with a focus on enhancing creative potential. Research has been conducted into the development of single piece woven garments (Piper and Townsend 2016; Bhattacharya and Koranne 2011; Wang et al. 2011; and Ng et al. 2010). This research contributes to knowledge within the specialism of footwear. In the area of craft-based design, it contributes an empirically relevant design process model that considers the role and viability of craft practice within commercial design.

\section{Approaches to Design: Idea Generation}


This section discusses three contrasting approaches to the design process at the idea generation stage, which is the point when design ideas are conceived. This stage is creative and holistic and occurs before an idea is developed and made to work in a practical sense (Tovey 1997: 10).

\section{D Non-Digital Design}

Drawing by hand is a common method used in footwear and other disciplines to generate ideas. It has been noted as crucial to the creative process (Lawson and Loke 1997: 172). Purcell and Gero (1998: 392) discuss how drawing can develop the form of an object, by retrieving information from the long-term memory and bringing attention to alternative aspects that lead to novel interpretations. This theory was previously introduced by Schön (1992a: 5) who describes it as 'seeing-drawing-seeing' and states that drawing aids the generation and evolution of design ideas. Additionally, Schön (1992b) reports on the detailed and ingrained knowledge of a design that can be gained through the drawing and re-drawing of a form by hand.

\section{D and 3D Digital Design}

The use of digital design methods can yield a number of benefits, such as time efficiency (Cross 2001: 46; Sennett 2009: 39; Sweet 2013: 31; Tovey, 1997: 18) and the ability to create variations on a design (Zaman, Özkar and Çagdas 2011: 225; Zequn and Rui 2010: 223). They can enable designers to generate complex forms and visuals that would not otherwise be possible (Lawson 2002: 327; Philpott 2012: 56; Sweet 2013: 31). This potential for new opportunities can aid creativity (Lawson 2002: 327) although it has been identified in a number of studies that the use of computer aided design (CAD)/computer aided manufacturing (CAM) in the early stages of the design process can restrict it (Evans et al. 2000: 189; Lawson and Loke 1997: 174; Treadaway 2007: 46). The isolated use of $\mathrm{CAD} / \mathrm{CAM}$ has been found to remove materiality and the ability to gain embodied knowledge through touch (Philpott 2012: 60). In response to this, hands-on computing solutions have been developed to provide a suitable method that suffices both creative and practical needs (Evans et al.2005: 489). However, at present, they are unable to replicate realistic interaction with materials as an instinctive process (Evans et al. 2000: 193; Philpott 2012: 60). Therefore, the use of digital design is commonly employed to address practical concerns such as time efficiency and may have a negative impact on creativity and spontaneity.

\section{D Non-Digital Hands-On Design}

In hands-on woven textile design, the early stage of idea generation typically consists of sampling on a loom (Wilson 2001: 14-15). Touch is particularly important in textile design (Philpott 2012: 54); interacting with materials can contribute to the development of form (Leader 2010: 413; Philpott 2012: 54) and inform creative thought (Treadaway 2007: 35). In some situations, hands-on making can also contribute to the development of novel materials (Yair and Schwarz 2011: 312) meaning that it is a viable approach to innovation. Flaws in materials can be identified by developing and experiencing them first-hand (Sennett 2009: 159), enabling designers to make adjustments where necessary. It is possible for CAD systems to store and use information of material properties in order to undergo testing in a digital format (Adanur and Vakalapudi 2013: 716). However, the software is developed towards a function-led industry and in aesthetically driven design, products also evolve through a number of subjective alterations (Wallace and Press 2004: 42). 
While there is the potential for significant advantages in the use of making as a tool for idea generation, it may not always be possible to work in this way due to practical constraints. Within the context of using a woven textile approach to sandal design, one problem could lie in the availability of weaving equipment which is generally bulky and noisy in comparison to methods such as drawing. Time and cost are the main challenges, with hands-on making often being a slow and expensive process (Philpott 2012: 61). This would generally need to be compensated for elsewhere in the design and development cycle or have significant benefits in the final outcome.

\section{Approaches to Design: Design Development}

Design development is the point at which the design ideas are refined and made to work in a practical sense. This section discusses the suitability of outputs from different design approaches in aiding this stage of the process.

\section{D Digital and Non-Digital Design}

2D technical working drawings can be created by hand or using digital software. This is common within footwear design and specification sheets are generally used to communicate design ideas to the sample room for prototypes to be constructed (Schaffer and Saunders 2012: 156). However, there are limitations for two-dimensional communication of 3D products (Tovey 1997: 26). For example, when refining a design on paper or on screen, it is possible that the scale and proportions may not translate into three-dimensions (Glanville, Worswick and Golding 1934: 103; Sennett 2009: 41). Consequently, there is potential for misinterpretation and 2D representations can lead to issues in the understanding of design intent. The efficiency of this method is much greater than that of three-dimensional techniques (Tovey 1997: 11), which is a significant factor for commercial designers. The use of $2 \mathrm{D}$ representations is common in the communication of designs within the footwear industry (Schaffer and Saunders 2012: 156-157). This must be considered for the successful integration of novel approaches, such as hands-on weaving, which can support current methods rather than fully replace them.

\section{Representational 3D Digital and Non-Digital Design}

3D representations can consist of digital models or hands-on modeling using materials which are different to those intended for the final product. The ability to see an object in 3D can allow for the form to be refined and provide a realistic representation (Jimeno-Morenilla, Sánchez-Romero and Salas-Pérez 2013: 1371).

Digital 3D models can speed up design and development (Cross 2001: 46; Sennett 2009: 39; Sweet 2013: 31; Tovey 1997: 18) and aid accuracy (Sennett 2009: 81), reliability in terms of memory (Lawson 2002: 328) and organization (Tovey 1997: 18). The availability of rapid prototyping has meant that CAD/CAM methods are now much more accessible (Evans et al. 2000: 188; Philpott 2012: 69), providing designers with the ability to effectively model designs. The disadvantage of using 3D CAD as opposed to physical modeling is that what is produced on screen is actually a 2D representation of the 3D model and manipulation of that model may lack control (Joneja and Kit 2013: 252). The key benefits of CAD/CAM systems appear to relate to efficiency rather than contributing to creative thought processes. In footwear design, digital 3D modeling has been found to slow down the design process (Antemie, Harnagea and Popp 2012: 415) leading to the retention of hand methods (Zequn and Rui 2010: 222). 3D CAD may become more relevant in footwear design if improvements in efficiency can be made and more appropriate software developed (Antemie et al. 2012: 415; Azariadis 2013: 321). 


\section{Prototypes and Material Samples}

A wealth of knowledge can be acquired from physical objects (Cross 1982: 224) and when designers construct prototypes using the same methods intended for production they may be reproduced almost directly by manufacturers. This process can also extend the designer's knowledge of 'materials, processes and technologies' (Lommerse, Eggleston and Brankovic 2011: 391) and, in turn, there may be a greater chance of success in the outcome.

While there are limitations associated with communicating designs using representational media (Sweet 2013: 391; Tovey 1997: 26), success in its use can be aided by knowledge gained through prior design experiences (Cross 2004: 432). When using techniques and materials which are widely known, hands-on making by designers for product development may not return many, if any, advantages. Schön (1992a: 4) presents a theory that knowledge can be gained through both making by hand and other representational design activities. Therefore, gaining a greater understanding of a design is not exclusive to hands-on making. However, the way in which designs are presented and translated by product development teams and manufacturers is another consideration. An expert designer may be able to use prior knowledge and representational methods to generate ideas that will work in practice but, if designs are not conveyed effectively to those who construct them, time may be wasted through unsuccessful sampling. Transportation of physical samples presents issues regarding efficiency although the benefits could make it worthwhile in a relevant design context. For example, for a brand developing products that are innovative or using construction methods that are not yet established with the manufacturer, having physical samples to communicate ideas may ultimately save time.

\section{Methods}

Practice-led action research was undertaken in the form of a sandal design project that incorporated hand weaving. The data collection took place over a period of 20 weeks and design activity was carried out on 46 separate days with an average of 3.6 hours per day.

\section{Practitioner as Researcher}

Nimkulrat (2012: 1) states that, "positioning craft practice in a research context can facilitate the reflection and articulation of knowledge generated from within the researcherpractitioner's artistic experience'. In this respect it is possible to access knowledge that may not be derivable from other sources (Evans 2010: 8). The background of the first author as a practicing footwear and textile designer was pertinent to the decision of employing practice to support data collection. Throughout the article the first author is referred to as the 'designer' in their role as practitioner. The co-authors were involved in periodic discussions relating to the design project and inputted into the theoretical and methodological elements of the research.

There are difficulties associated with the communication of knowledge generated through practice. Consisting of tacit knowledge or the design decisions and judgments of an expert, data collection and analysis is not straightforward. Niedderer and Townsend (2010: 8) identified that tacit knowledge can be recorded, in part, by documentation through both written and visual media. In this study, the outputs of practice along with written and visual documentation were all considered as forms of data.

\section{Action Research}


Action research is described by Birley and Moreland (1998: 34) as 'research conducted by a professional into their own activity with a view to bringing about an improvement in their practice'. The aforementioned experience of the first author meant that action research was applicable in discovering and evolving processes through practice. Dick (1993) describes action research as a cyclic process consisting of planning, action and review. During the case study tasks were planned, put into action through practice and reviewed using reflective documentation. The design processes and outcomes evolved through these continuous cycles. Additionally, a series of design outcomes consisting of fully-fashioned, or single piece, woven sandal uppers were produced. The 'upper' being a term for the section of the shoe that holds the sole to the foot.

\section{Data Collection}

Diaries and, more specifically, 'end-of-the day reporting' (Pedgley 1997: 220) was used as a key method of recording the design process. This was suitable due to the balance between accuracy of information and having minimal interference with the normal design process (Pedgley 2007; 1997). The diary entries consisted of hand written reflections and observations documented alongside information such as the date, sheet number and a record of other corresponding information and outcomes.

Where visuals were necessary, photographs were annotated digitally in what the researchers describe as 'supporting documents'. These files and were archived and linked to the corresponding diary sheet. In addition to full diary entries, Pedgley (2007) utilized a sheet to record activities when 'no detailed entry' was required (p.474). The method was built upon in this study via the development of a 'diary log' system where all activities were recorded and, if no detailed diary entry was necessary, a short comment could be made. Information including time spent and documentation of the corresponding codes of the data were included. This enabled the recording of all data sources and their relationship to the design project as a whole to be stored in one place. All design outcomes were scanned and logged in a spreadsheet, building on Pedgley's use of digital archiving (2007: 478).

A summary of the different formats of data collection are outlined below, including the amount of data collected. Three types of data consisted of documentation that took place outside of the normal design process and four consisted of the normal outcomes of practice:

\section{Documentation}

- $\quad$ Diary sheets x 30

- $\quad$ Diary log entries x 46

- $\quad$ Supporting documents x 23

\section{Outcomes}

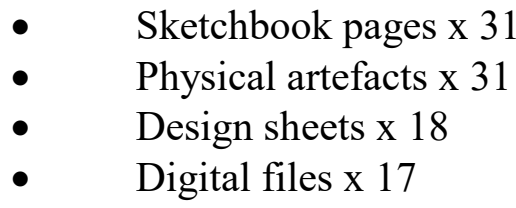

- $\quad$ Sketchbook pages x 31

- $\quad$ Physical artefacts x 31

- $\quad$ Digital files x 17

Analysis was undertaken using qualitative methods (Miles and Huberman 1994) and the data was first annotated and organized into design activities. Annotations enabled reflection with the aim of providing insights into the thought processes and tacit knowledge employed.

A map of the design process was created to organize the data into a logical format (see Figure 1). Each activity, represented by a piece of text, was assigned to a design stage. Descriptive 
and insightful data was linked to them and connections between activities were made relating to what led to or informed another process. For example, 'Creating yarn wraps' led to/informed 'drafting a warp'. Colour coding was used within the map to represent whether the activities led to/informed the final designs, whether they did to a limited extent, or they did not. Once the data had been mapped, codes were assigned to the activities based on what they involved. Some initial categories were identified from the research questions and literature review and they evolved through the coding process. The codes applied along with their definitions are presented in Figure 2.

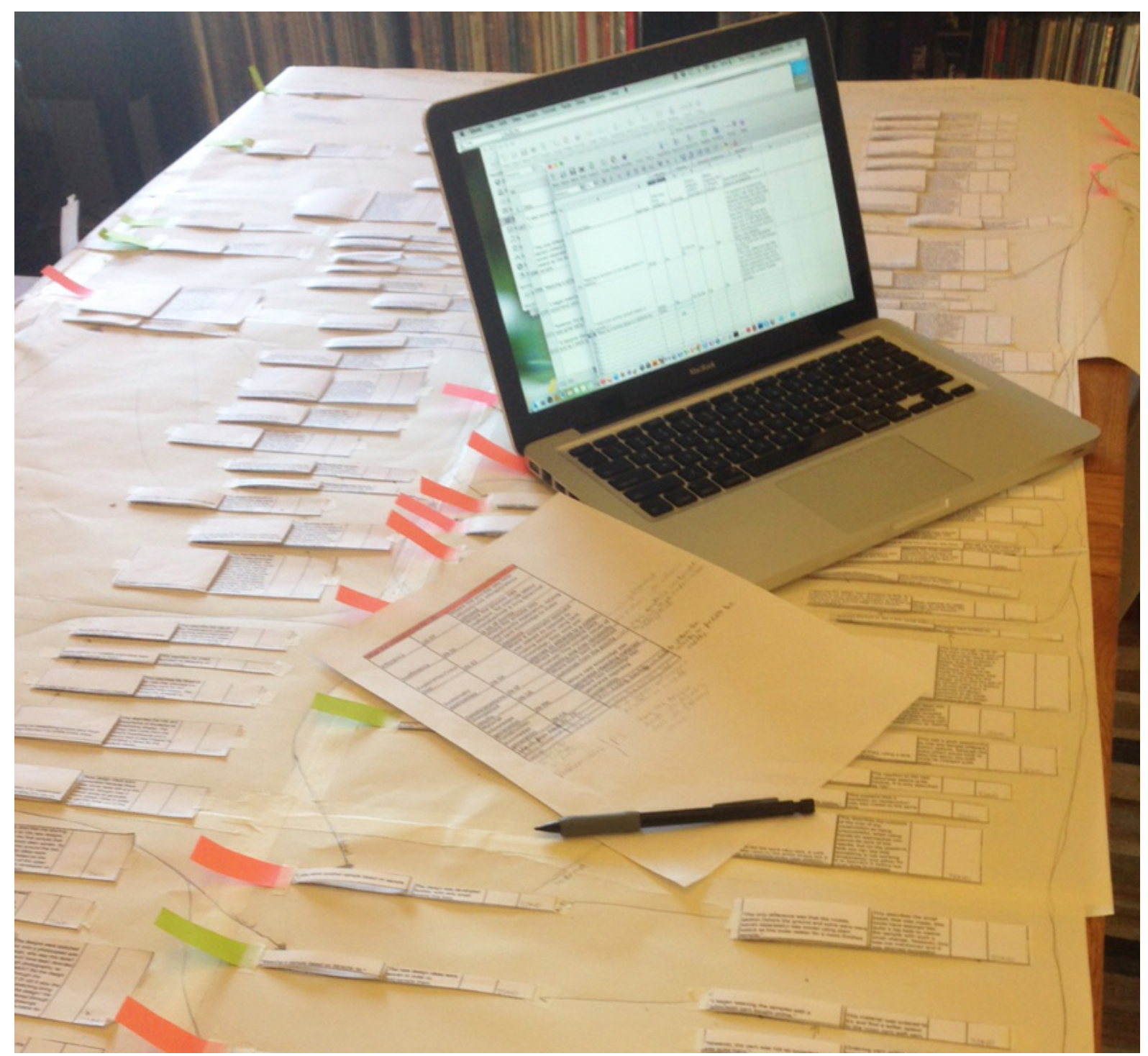

Figure 1: Analysis map of the design process data, (C) Jenny Pinski. 


\begin{tabular}{|l|l|}
\hline What the process involved & Where the process was time efficient, cost efficient and/or labour efficient \\
\hline Efficiency & $\begin{array}{l}\text { Where the process was inefficient, for example labour intensive, time } \\
\text { consuming, and/or expensive }\end{array}$ \\
\hline Inefficiency & $\begin{array}{l}\text { Where the process was significantly explorative or intuitive, relying on tacit } \\
\text { knowledge to make decisions }\end{array}$ \\
\hline Exploration/Intuition & $\begin{array}{l}\text { Where a systematic approach was utilised as opposed to or as well as } \\
\text { making decisions using tacit knowledge. For example the activity was pre- } \\
\text { planned or adhered to a system }\end{array}$ \\
\hline Systematic approaches & $\begin{array}{l}\text { Where issues or problems of the suitability of the process were involved or } \\
\text { highlighted. This includes issues of over complexity }\end{array}$ \\
\hline Issues/problems (process) & $\begin{array}{l}\text { Where there were issues or problems with the outcomes, either finished or } \\
\text { as a work in progress }\end{array}$ \\
\hline Issues/problems (outcomes) & $\begin{array}{l}\text { Where there were unexpected outcomes from the activity or where } \\
\text { something was brought to light that hadn't been considered }\end{array}$ \\
\hline Unexpected results & Where new knowledge was generated specifically relating to materials \\
\hline $\begin{array}{l}\text { Material knowledge } \\
\text { generation }\end{array}$ & Where new knowledge was generated specifically relating to construction \\
\hline $\begin{array}{l}\text { Construction knowledge } \\
\text { generation }\end{array}$ & Where the activity aided decision making in the design process \\
\hline Aided decisions & $\begin{array}{l}\text { Where the activity led to a significant change in direction or re-think of the } \\
\text { outcomes }\end{array}$ \\
\hline Led to a change in direction & Where the designer dealt with problems or issues successfully \\
\hline Successful problem solving & Wnsuccessful problem \\
solving
\end{tabular}

Figure 2: Categories and definitions used for data analysis, (C) Jenny Pinski.

\section{Findings and Discussion}

Once the data had been organized and categorized, it was possible to search for patterns within it. This section presents the integrated design process that was utilized and discusses the findings at each stage.

\section{An Integrated Design Process}

Figure 3 depicts the design process undertaken in the study. It relates to a process model by Wilson (2011: 58) and the action research data. The presented process was not linear and stages were revisited throughout. The approaches used are presented at each stage and the stages themselves relate to the function of the activity, providing a loose order in which the process generally progressed. They can be summarized as follows:

Concept development - The initial concept was conceived and developed and it was conducted at the beginning in isolation from the other stages outside of the documented design cycle and therefore specific approaches are not included in Figure 3.

Initial research - The initial concept was researched to gain information and details that were important in providing a focus for the design project. It accounted for approximately 14 per cent of the total time spent. It involved creating yarn wraps, where yarns are wrapped around a piece of card to visualize them under tension, and drawing to the explore colour, scale and composition. Searching online and creating mood boards helped the designer to develop the theme.

In-depth research - In-depth research accounted for 41 per cent of the recorded design process. It involved in-depth exploration of materials and constructions. 


\section{Concept development}

A 2D/3D Hybrid/Non-tangible approach was used
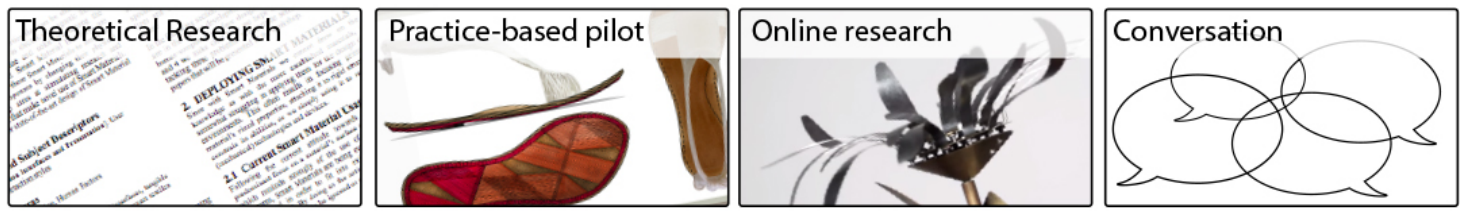

Initial research
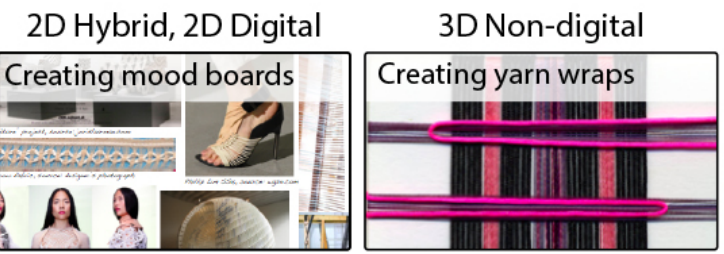

2D Non-digital

Drawing

2D Digital

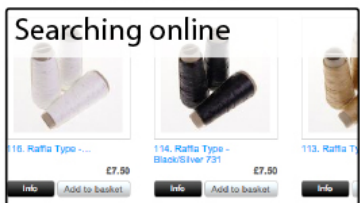

In-depth research
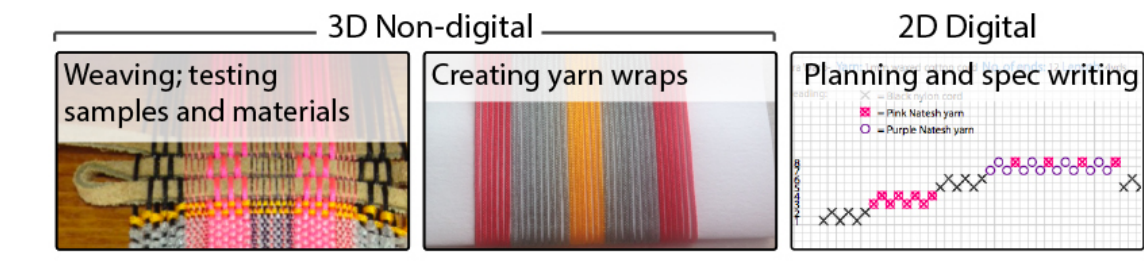

2D Non-digital

Planning drawings and note making

2D/3D Hybrid,

Idea generation

2D/3D Non-digital
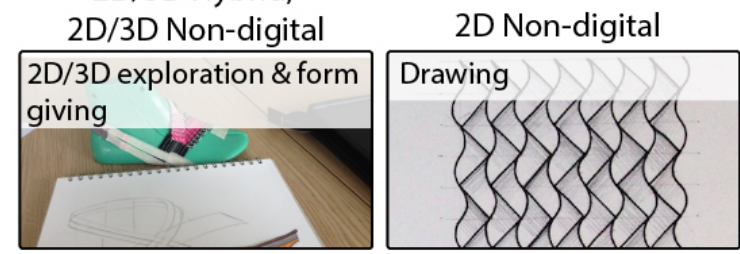

2D Hybrid

Combining digital and hand drawings

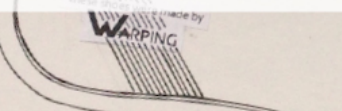

Design development
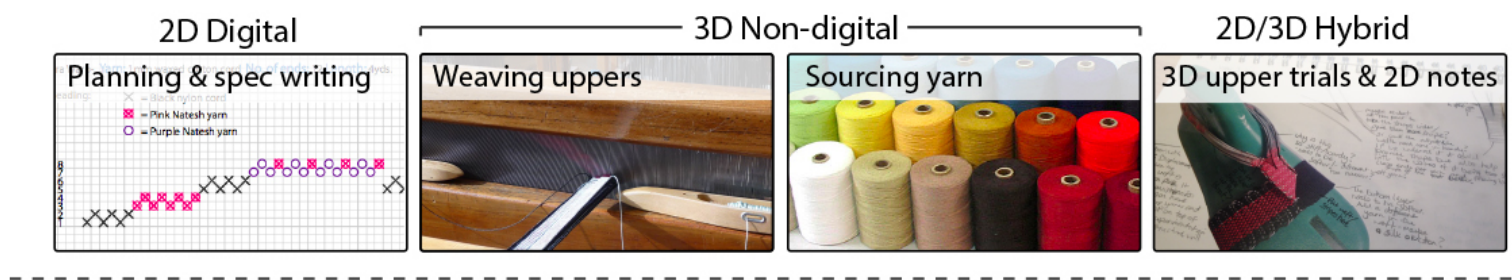

\section{Presentation}

2D Hybrid

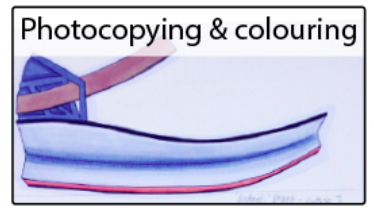

2D/3D Hybrid

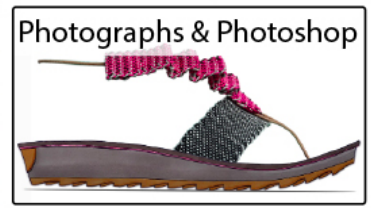

Figure 3: Illustrated diagram of the design process, methods and approaches used in the case study, (C) Jenny Pinski. 
Idea generation - Initial design ideas were generated using drawing and quick methods of 3D modeling. This stage accounted for 20per cent of the overall time spent on the project.

Design development - Initial design ideas were selected, trialed and refined, developing them into something that was fit for purpose and could be replicated. It accounted for 29 per cent of time on the project and was mainly undertaken through weaving the sandal upper designs by hand.

Presentation - Final designs were presented by bringing together the required elements as product proposals. It accounted for 4 per cent of the total time spent and digital software was used to consolidate design components in different formats.

\section{In-Depth Research}

The discussion of the findings begins at the in-depth research stage as it is the first point where hands-on weaving was employed. Three approaches were used, 3D non-digital, 2D digital and 2D non-digital. The majority of in-depth research was conducted using 3D nondigital methods, largely consisting of weaving to test materials and constructions. 40 per cent of the 3D non-digital activities informed the final designs and an additional 40 per cent did to a limited extent. The approach, therefore, appeared to be suitable at this stage but with some uncertainty.

Figure 4 compares the coding of 3D non-digital activities at the in-depth research stage, grouping them by whether they informed the final designs; informed them to a limited extent; or did not inform them. The axis of the graph represents the number of times that the codes were applied to activities. For example, 'systematic approaches' were used in three activities that informed the final designs, two activities that informed them to a limited extent and one that did not inform them at all. By identifying the attributes involved in each of the activities it was possible to identify patterns in the qualities that were deemed as being most and least successful in informing the final outcomes. The activities that informed the final designs were more efficient, systematic and aided decisions. In the activities that did not inform the final designs, problem solving was unsuccessful and there was a higher degree of inefficiency. While systematic approaches appeared to inform the designs more than explorative or intuitive ones, the material knowledge relating to the final designs was gained through unexpected results. A nylon cord that had been chosen for its thickness and strength was found to have shape-holding properties when woven. This was unexpected and meant that it was a good choice for creating 3D objects that need to hold their form (such as sandals). Additionally, 3D detailing was built into some of the designs, including an adaptable element where the wearer can alternate between having a pleated upper strap or a flat one. This was inspired by the properties of the material. The corresponding activity only informed the final designs to a limited extent but provided a starting point for further exploration of the material. In addition, material knowledge generation was prominent in the activities that did not inform the final designs. This shows that in-depth research through hand weaving has the potential lead to novel design proposals through unexpected results. However, it is uncertain, time consuming, and experimentation may lead to dead ends. This means that it would be problematic to incorporate it into a seasonal design cycle with strict time pressures. 


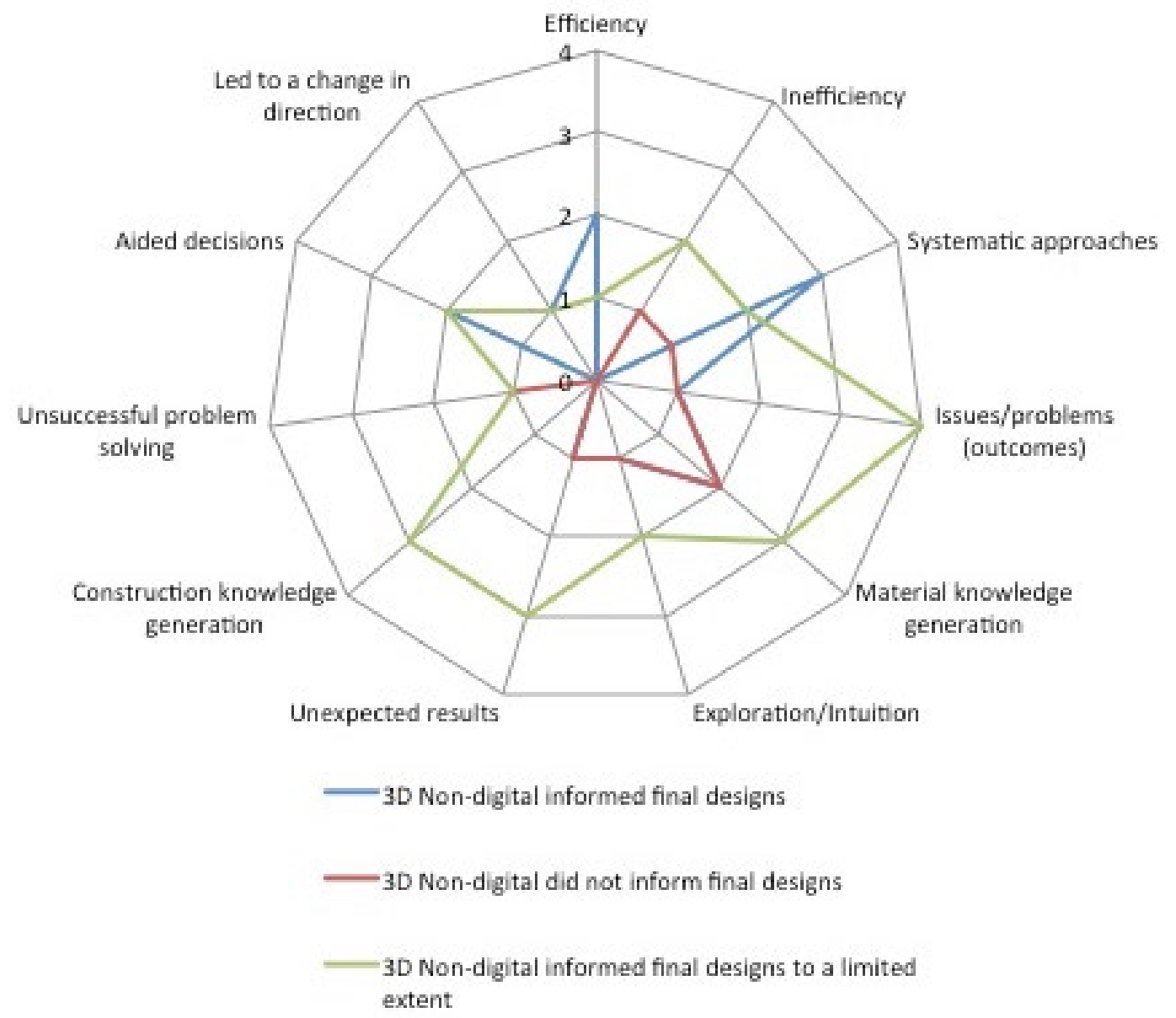

Figure 4: Radar diagram showing the frequency of codes applied in the 3D non-digital activities used at the in-depth research stage and whether they informed the final designs, (C) Jenny Pinski.

It is not uncommon for commercial companies, particularly performance or design-led brands, to engage with research and development (R\&D) activities that are outside of the seasonal product creation cycle (Park 2007). This model appears to be a suitable approach to integrating craft practice within a commercial setting. However, in order for a company to justify the time and financial investments necessary, there must be sufficient potential and demand for design innovation.

\section{Idea Generation}

At the idea generation stage, four approaches were used: 2D non-digital, 2D/3D hybrid, 2D/3D non-digital and 2D hybrid. The most prominent was 2D non-digital, which generally consisted of drawing by hand. This appeared to align with the literature review that indicated the suitability of drawing at this stage. It was notable, however, that the majority of $2 \mathrm{D}$ nondigital activities did not inform the final designs and all were related to the design of the outsole. Attempts were made between other activities and the immediacy and efficiency of the approach enabled this. The other 2D method was a hybrid approach and, again, this was used for the outsole design. The 2D approaches were generally identified as being intuitive/explorative and involved some elements of efficiency.

2D/3D approaches (non-digital and hybrid) were used for the upper design. They consisted of forming samples around a 3D model of the desired foot shape, known as the 'last' to generate 
ideas. These were then developed and recorded in 2D through sketching (see Figure 5). This process was much faster than the weaving employed at both the in-depth research and the design development stages and efficiency was a prominent theme in the analysis. Form was generated in 3D and then taken into a 2D format and there was consistent interaction between $2 \mathrm{D}$ and $3 \mathrm{D}$ methods. The 2D activities recorded and evolved the designs. Visualizing the design in different formats provided alternative views and aided the development of ideas. The 3D element helped to manage the complex process of designing a woven textile and sandal in parallel.

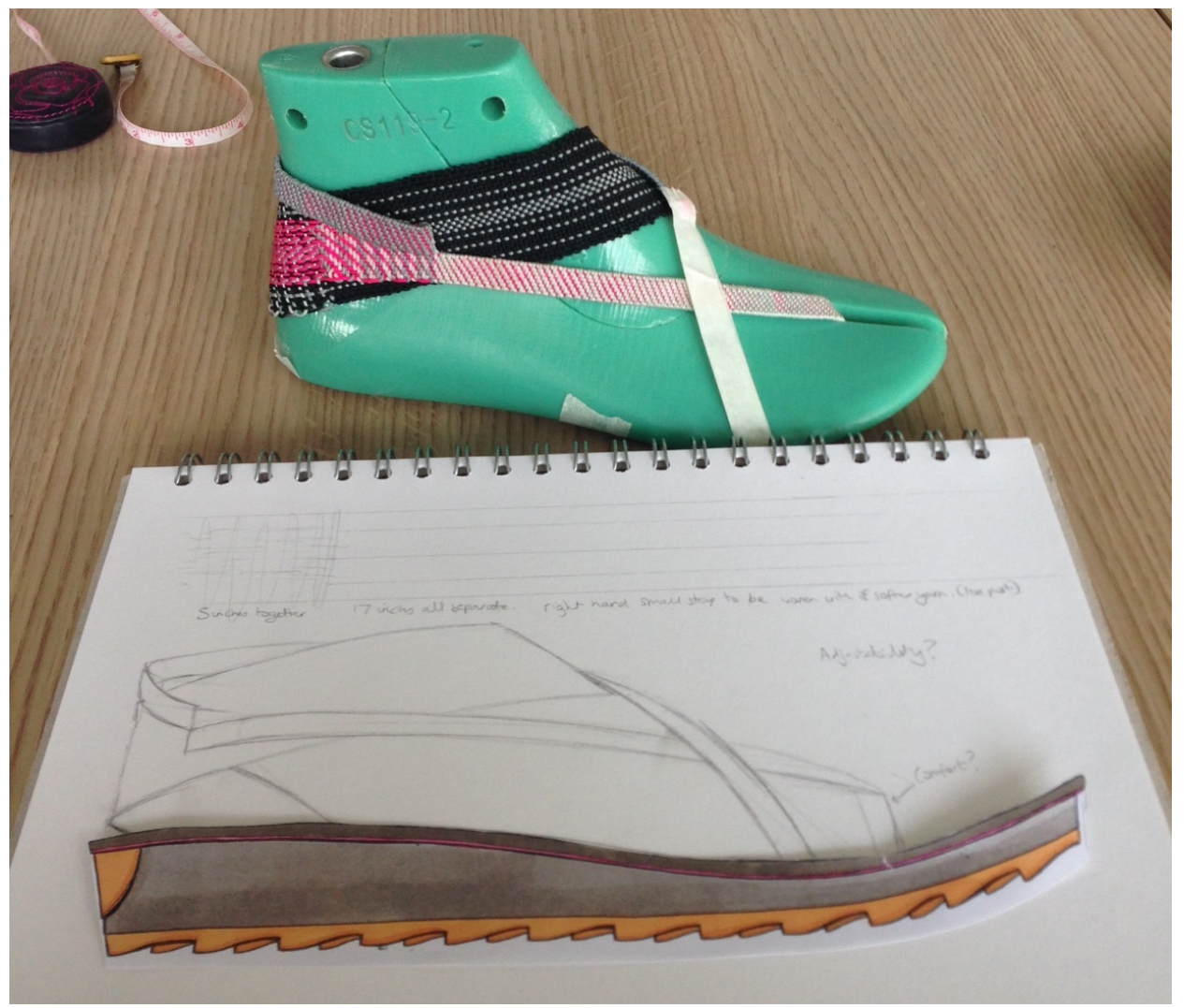

Figure 5: An example of 2D/3D approaches to idea generation involving sketching and quick modeling techniques, (C) Jenny Pinski.

\section{Design Development}

At this stage, 2D digital, 3D non-digital and 2D/3D hybrid approaches were used. The most prominent was 3D non-digital, with the majority of these activities leading to the final designs. The 2D digital approaches all refer to the preparatory task of detailing the set-up of the loom (see Figure 6). The data analysis revealed that these activities were systematic and efficient. This appears to reflect the theory presented in the literature review that digital processes lend themselves to technical tasks, leading to benefits in efficiency and in this respect can support craft practice. The 2D/3D hybrid approach refers to the evaluation of samples through trying out uppers on the last, photographing them and making notes and sketches to suggest changes. This was a very similar approach to that used at the idea generation stage and allowed the designer to evolve the design in 2D and 3D. 


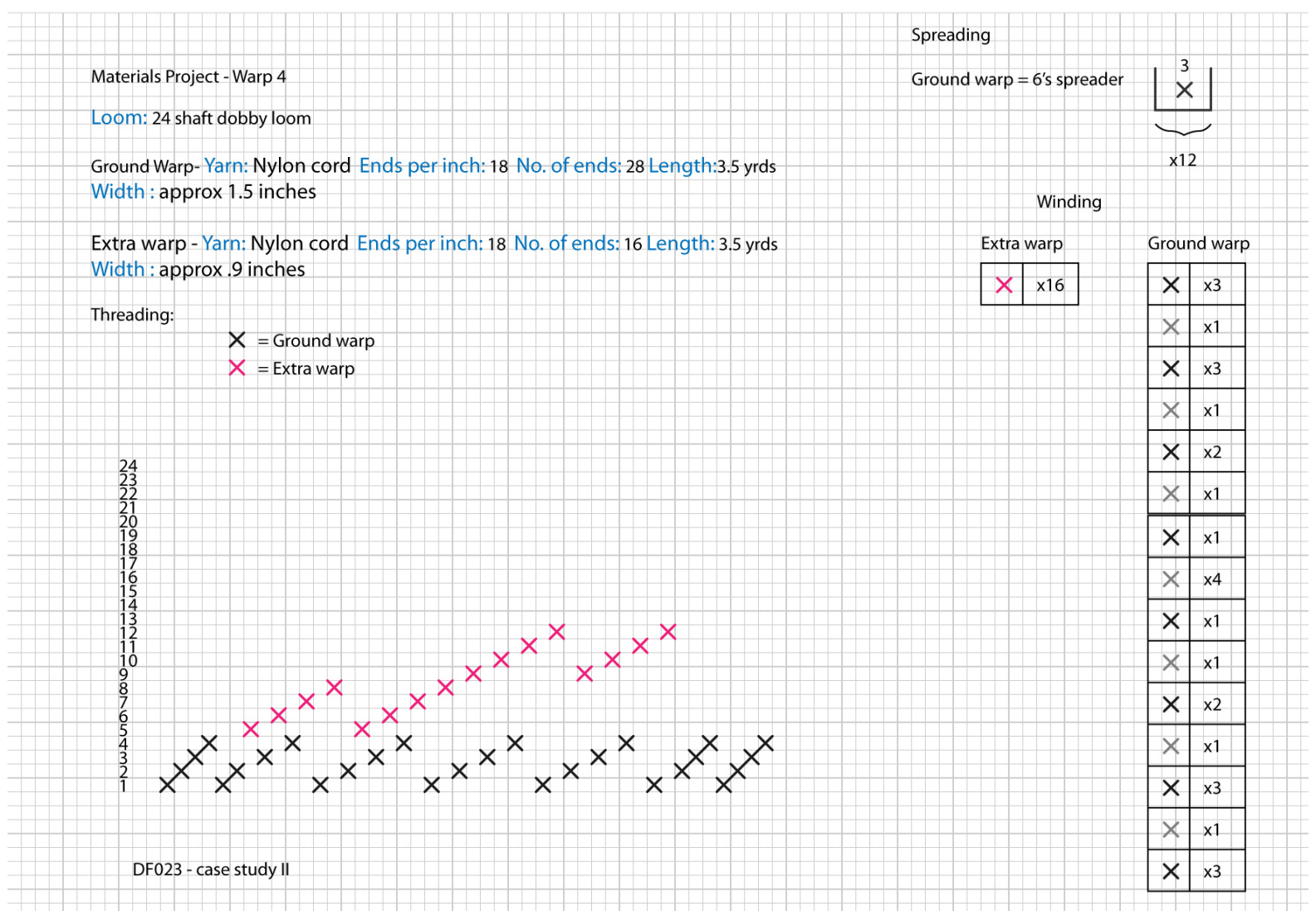

Figure 6: Technical specification for setting up the loom generated using a 2D digital approach, (C) Jenny Pinski.

The 3D non-digital approach mainly consisted of weaving upper designs along with some preparatory tasks such as creating yarn wraps and setting up the loom. The chart in Figure 7 illustrates comparisons in the frequency of codes applied to the 3D non-digital activities that informed the final designs and those that did not. There were no activities at this stage that informed the final designs to a limited extent. Exploration/intuition was prominent in the activities that informed the final designs and did not feature in those that did not. It is possible that this exploration and intuition made the design development successful. Alternatively, it may be that when a design was seen as having more potential, the designer felt that it was appropriate for it to evolve intuitively. Additionally, issues and problems were relatively prominent in both scenarios, although problem solving only featured in the activities that informed the final designs, again indicating the lack of a perceived need to develop the ideas that were not seen as having potential. When an activity led to problems that the designer would struggle to resolve or did not consider as being worthy of resolving, they were quickly abandoned. For example, alternative structures and materials were tried and dismissed when they did not work as expected. The designer noted that when trialing materials purchased online that, 'the yarn was not as expected and was quite hairy. It became clear that it would not be suitable.' Tacit knowledge was employed to decide if a problem could be solved or was worth solving and whether there was a need for further exploration. It is therefore possible that instances where there was a lack of exploration/intuition and problem solving was a consequence of an unsuccessful design as opposed to a reason. Sennett (2009: 159) remarks on the immediacy experienced by designers when engaging with materials in a design project. The designer experienced this during the case study and the ability to refine the designs through instinctive decisions during the making process was a notable benefit. Systematic approaches were prominent across both sets of data which points to a general systematic process being utilized at this stage. 


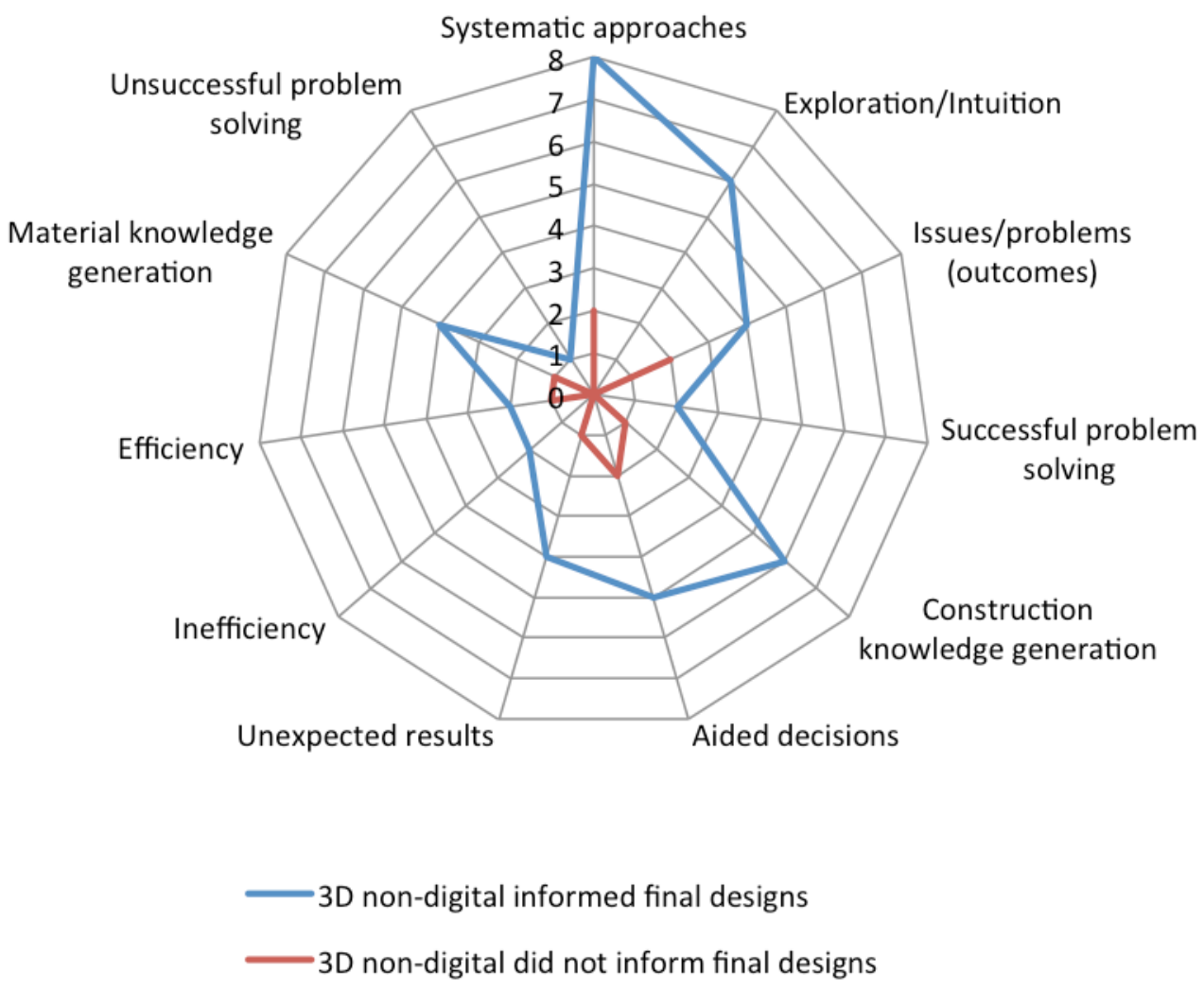

Figure 7: Radar diagram showing the frequency of codes applied in the 3D non-digital activities used at the design development stage and whether they informed the final designs, (C) Jenny Pinski.

\section{Presentation}

2D hybrid and 2D/3D hybrid approaches were involved at the presentation stage. As this involved only three activities, it is difficult to identify patterns. However, it is notable that all of the approaches used at this stage were hybrid and the digital element was identified within the data as being 'very useful in bringing together the full design as a visualization.' The example in Figure 8 shows the presentation of a hand-woven upper and a hand-drawn outsole as a single digital image. Digital methods enabled the consolidation of design components in different formats. Digital methods also have the potential to bring a $2 \mathrm{D}$ design to a $3 \mathrm{D}$ format through the use of 3D printing. This would be more costly and time consuming although it would allow the designs to be presented as a physical object which would provide a more accurate representation of the design proposal.

\section{Design Outcomes}

The final designs benefitted from the approach used, the careful consideration of form, material and construction in parallel led to the creation of a novel, adaptable pleated design, informed by the material properties that would not have been conceived on paper. In addition, it was reflected upon that the constructions are stitch-free and zero or low-waste as the seams have been built into the woven structure. 


\section{Materials study sandal - upper 1}
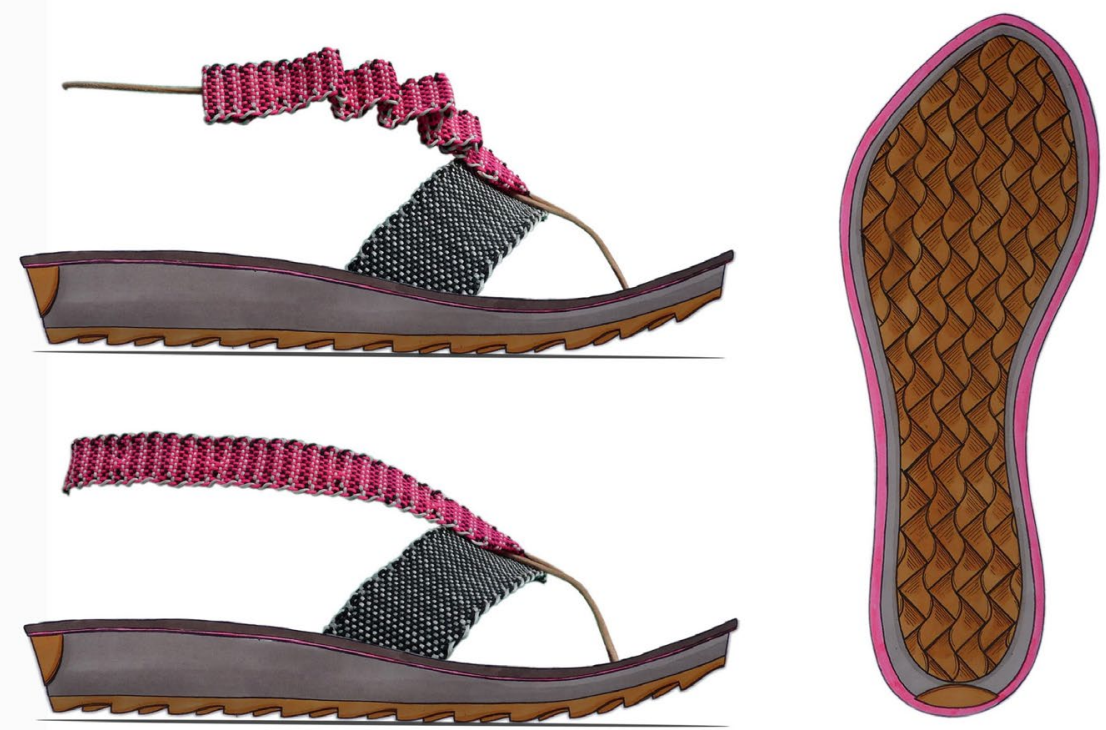

DF026

Figure 8: Design presentation sheet generated using 2D/3D hybrid approaches, C Jenny Pinski.

\section{Conclusions}

The findings of this study indicate that there is potential for a hands-on woven textile approach to sandal design in some circumstances and contexts. Figure 9 shows a suggested design cycle model that integrates a hands-on woven textile approach into sandal design. It outlines the stages that were undertaken during the design project, showing an overall structure as a suggested workflow. The key roles of hands-on interaction with materials at each stage are also presented. Whilst the suggested design cycle is based on data analysis of a footwear design project, the process has been presented in a generalized fashion so that the model may be applicable to other disciplines and design specialisms. The process is not linear and, while there is likely to be a general progression in-line with the order from top to bottom, the arrows depict the way in which stages may be returned to. Additionally, on-going in-depth research has the potential to feed into the process at any stage. The research revealed the concept development stage as an exception to this and it is conducted in isolation at the beginning of the process.

Hands-on interaction played different roles at different stages of the design cycle and this has informed the structure of the suggested model. For example, the use of weaving to test yarns at the in-depth research stage can be time consuming and uncertain in terms of outputs. However, innovation may occur through unexpected results and this can be valuable in informing design concepts. Therefore, the in-depth research stage has been positioned outside of the normal design cycle as an on-going activity meaning that it is not subject to the same time pressures experienced by the rest of the design process. 


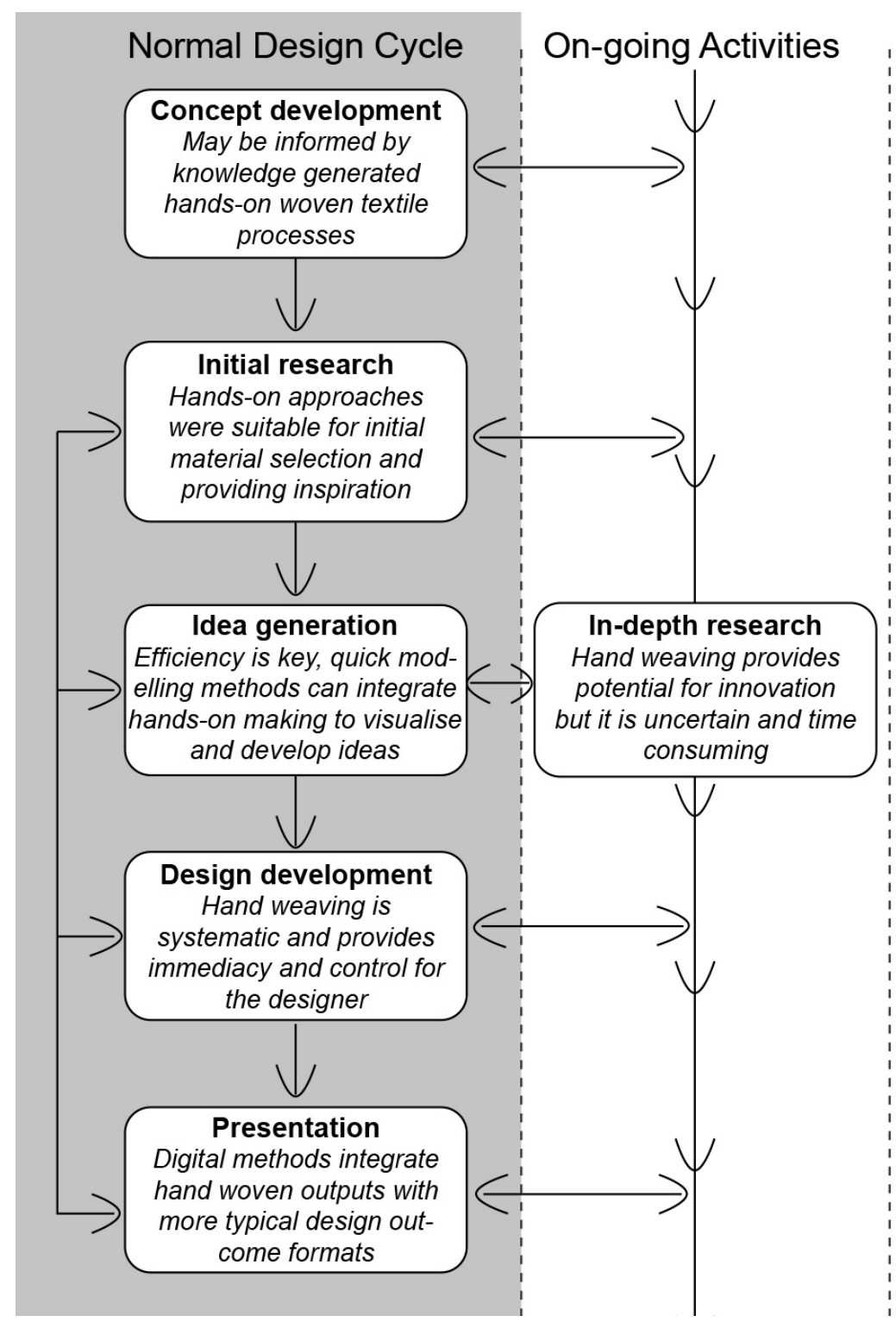

Figure 9: Proposed integrated design process workflow with the key roles of hands-on exploration with materials at each stage, (C) Jenny Pinski.

At the design development stage, hand weaving required substantial time investment from the designer. However, the majority of 3D non-digital activities led to the final designs. Where issues and problems were encountered, the designer was able to gain a first-hand understanding of the problem and decide whether to resolve it or reject the design. The immediacy with which tacit knowledge could be employed was a significant benefit and subjective decisions can be incorporated alongside technical ones. The ability to rapidly generate new ideas appeared to be a key feature at the idea generation stage along with the use of 2D and 3D approaches in conjunction with one another. Viewing and evolving the designs in these formats helped to manage the complexity of designing sandals and textiles in parallel. Digital software was used to consolidate the outputs in a number of different formats for presentation. While this was achieved in 2D, there is scope for 3D CAD and 3D printing to provide a more accurate representation of the final design, leading to potential benefits in accurate communication. However, the full potential and benefits may only be present when working with novel materials, processes or constructions as representational media is deemed to be sufficient when working with those that are widely known.

Interaction with materials in the design process meant that the collection was informed directly by the construction potential and the properties of the woven upper material. The 
findings indicated that new knowledge of materials and constructions could be gained through craft processes. This can lead to design innovation, addressing a competitive need and benefitting the wider economy. The research demonstrates the importance of materiality in facilitating innovation at a time when footwear design research commonly focuses on digital methods for efficiency. Therefore, the need to consider the impact of reducing materiality through the sole use of digital methods is highlighted. The craft-based woven textile approach used in this study led to benefits in the final design outcomes, which consisted of a range of fully-fashioned sandal uppers that are woven as a single piece and are low or zero waste. Current research in the area of weaving for zero-waste outcomes is generally focused towards the development of garments. However, this has not yet been fully explored within the specialism of footwear. This research has identified it to be a viable method of footwear construction that may reduce manufacturing waste. There is also potential to incorporate multi-layer constructions whereby softer linings can be integrated with more durable outer layers for example without the need for glues and solvents. Therefore, this suggests future research opportunities for the development of zero-waste design and production in footwear. Additionally, further investigation of a craft-based woven textile approach within other disciplines and design specialisms will enable development and generalization of the process model beyond footwear.

\section{References}

Adanur, S., and Vakalapudi, J. S. (2013), 'Woven fabric design and analysis in 3D virtual reality. Part 1: computer aided design and modeling of interlaced structures', Journal of the Textile Institute, 104: 7, pp. 715-723.

Antemie, A., Harnagea, F. and Popp, A. (2012), 'Advanced virtual footwear design, by rendering shoe models, instead of drawing', in Proceedings of The 8th International

Scientific Conference eLearning and software for Education, Bucharest, Romania, 26th-27th April, pp. 414-421, Frankfurt: C.E.E.O.L.

Azariadis, P. (2013), 'Finite Element Analysis Methods in Footwear Design', in R. S. Goonetilleke (Eds.), The Science of Footwear, pp. 321-340, Boca Raton: CRC Press.

Bhattacharya, S. S. and Koranne, M. (2011), 'Novel method of weaving three-dimensional shapes', International Journal of Clothing, Science and Technology, 24: 1, pp. 56-isepi: 63.

Birley, G. and Moreland, N. (1998), A practical guide to academic research, London: Kogan Page Limited.

Cross, N. (1982), 'Designerly ways of knowing', Design Studies, 3: 4, pp. 221-227.

Cross, N. (2001), 'Can a machine design?’ Design Issues, 17: 4, pp. 44-50.

Cross, N. (2004), 'Expertise in design: an overview', Design Studies, 25: 5, pp. 427-441.

Davidson, C. (2012), 'Investigating the suitability of laser sintered elastomers for running footwear applications', Ph.D. thesis, Loughborough: Loughborough University.

Dick, B. (1993), 'You want to do an action research thesis?'

http://www.aral.com.au/resources/arthesis.html\#a_art_whatisar. Accessed 17th July 2014.

Evans, M. (2010), 'Researcher practice: Embedding creative practice within doctoral research in industrial design', Journal of Research Practice, 6: 2, Article M16. 
Evans, M., Cheshire, D. and Dean, C. (2000), 'An investigation into the use of haptic modelling during industrial design activity' in Proceedings of IDATER 2000, Loughborough, 21st-23rd August, pp. 188-193, Loughborough: Loughborough University Department of Design and Technology.

Evans, M., Wallace, D., Cheshire, D. and Sener, B. (2005), 'An evaluation of haptic feedback modelling during industrial design practice’, Design Studies, 26: 5, pp. 487-508.

Glanville, F. Y., Worswick, B. and Golding, F. Y. (1934), Boots and shoes: their making, manufacture and selling, Vol.1: Pattern cutting and making, London: Pitman.

Goel, V. (1995), Sketches of Thought, Cambridge, Massachusetts: MIT Press.

Head, M. J. and Porter, C. S. (2011), 'Developing a collaborative design toolkit for the personalisation of running shoes', Design Principles \& Practices: An International Journal, 5: 6, pp. 303-325.

Jimeno-Morenilla, A., Sánchez-Romero, J. L. and Salas-Pérez, F. (2013), 'Augmented and virtual reality techniques for footwear', Computers in Industry, 64: 9, pp. 1371-1382.

Joneja, A. and Kit, F. S. (2013), 'Computer-Aided Design of Footwear', in Goonetilleke, (ed.), The Science of Footwear, Boca Raton: CRC Press, pp. 213-260.

Lawson, B. (1997), How designers think: the design process demystified. $3^{\text {rd }}$ ed. Oxford: Architectural Press.

Lawson, B. (2002), 'CAD and creativity: does the computer really help?', Leonardo 35: 3, pp. 327-331.

Lawson, B. and Loke, S. M. (1997), 'Computers, words and pictures', Design Studies, 18:2, pp. 171-183.

Leader, E. (2010), 'Materializing craft: Evaluating the effects of experiencing actual materials during the design process', Design Principles and Practices, 4: 4, pp. 405-418.

Liao, X. and Jiang, K. (2008), 'Upper automatic sewing technology based on image', in Proceedings of the IEEE International Conference on Information and Automation, $20^{\text {th }}$ $23^{\text {rd }}$ June, pp.524-526, IEEE.

Lommerse, M., Eggleston, R. and Brankovic, K. (2011), 'Designing Futures: A Model for Innovation, Growth and Sustainability of the Craft and Design Industry', Design Principles and Practices, 5: 4, pp. 385-404.

Maurtua, I., Ibarguren, A. and Tellaeche, A. (2012), 'Robotic solutions for Footwear Industry', in Proceedings of Emerging Technologies \& Factory Automation (ETFA), IEEE 17th Conference on, 17th-21st September, pp.1-4, IEEE.

Miles, M. B. and Huberman, A. M. (1994), Qualitative data analysis: an expanded sourcebook, London: Sage.

Ng, M. C. F., Wang, X., Hu, J. and Szeto, Y.C (2010), 'Shapeable stretch textiles via compound weaves for seamless woven fashion', Textile Research Journal, 80:12, pp. 1715- 
1724.

Niedderer, K., and Townsend, K. (2010), 'Craft Research: Joining Emotion and Knowledge', in Proceedings of Design and Emotion, $4^{\text {th }}-7^{\text {th }}$ October, Chicago: IIT.

Nimkulrat, N. (2012), 'Hands-on intellect: Integrating craft practice into design research', International Journal of Design, 6: 3, pp. 1-14.

Park, A. (2007), 'Nike CEO: Mark Parker', Time, 170: August, pp. 42.

Pedgley, O. F. (1997), 'Towards a method for documenting industrial design activity from the designer's perspective', in Proceedings of IDATER 97, Loughborough, pp. 217-222, Loughborough: Loughborough University Department of Design and Technology.

Pedgley, O. (2007), 'Capturing and analysing own design activity', Design Studies, 28: 5, pp. 463-483.

Philpott, R. (2012), 'Crafting innovation: The intersection of craft and technology in the production of contemporary textiles', Craft Research, 3: 1, pp. 53-74.

Piper, A. and Townsend, K. (2016), 'Crafting the Composite Garment: The role of hand weaving in digital creation', Journal of Textile Design Research and Practice, 3: 1-2, pp. 326.

Purcell, A. T. and Gero, J. S. (1998), 'Drawings and the design process: A review of protocol studies in design and other disciplines and related research in cognitive psychology', Design Studies, 19: 4, pp. 389-430.

Schaffer, J. and Saunders, S. (2012), Fashion design course, Accessories: design practice and processes for creating hats, bags, shoes and more, London: Thames and Hudson.

Schön, D. A. (1992a), 'Designing as reflective conversation with the materials of a design situation', Knowledge-Based Systems, 5: 1, pp. 3-14.

Schön, D. A. (1992b), 'Kinds of seeing and their functions in designing', Design Studies, 13: 2, pp. 135-156.

Sennett, R. (2009), The craftsman, London: Penguin.

Sterzing, T., Lam, W. K., and Cheung, J. T. (2013), 'Athletic Footwear Research by Industry and Academia', in Goonetilleke, (ed.), The Science of Footwear, Boca Raton: CRC Press, pp. 605-622.

Sweet, T. (2013), 'Instilling an awareness of phenomenology through a craft-centered design pedagogy', International Journal of Design Education, 6: 2, pp. 31-39.

Tovey, M. (1997), 'Styling and design: intuition and analysis in industrial design', Design Studies, 18: 1, pp. 5-31.

Treadaway, C. (2007), 'Digital crafting and crafting the digital', Design Journal, 10: 2, pp. $35-48$. 
Trends Business Research (2014), 'Measuring the Craft Economy: Defining and measuring craft: Report 3',

http://www.craftscouncil.org.uk/content/files/Measuring_the_craft_economy-v4.pdf. Accessed 20 August 2018.

Verdu-Jover, A. J., Gomez-Gras, J. M., Mira-Solves, I., and Martinez-Mateo, J. (2008), 'Alternative value creation strategies in the footwear industry: Exploring the role of production offshoring', in Proceedings of Industrial Engineering and Engineering Management (IEEE), 2008, International Conference, Singapore, pp. 1880-1884, Singapore: IEEE.

Vinet, A. and Caine, M. (2011), 'Design, manufacture, and evaluation of traction features on sprint footwear using laser sintered nylon-12 sole units', Journal of Sports Engineering and Technology, 225: 4, pp. 259-264.

Wallace, J. and Press, M. (2004), 'All this useless beauty: the case for craft practice in design for a digital age', The Design Journal, 7: 2, pp. 42-53.

Wang, J., Zhang, H., Lu, G. and Liu, Z. (2011), 'Rapid parametric design methods for shoelast customization', International Journal of Advanced Manufacturing Technology, 54: 1-4, pp. 173- 186 .

Wilson, J. A. (2001), A Handbook of Textile Design: Principle, Process and Practice, Cambridge: Woodhead Publishing.

Wilson, J. A. (2011), 'Core Design Aspects', Ph.D. thesis, Manchester: The University of Manchester.

Yair, K. and Schwarz, M. (2011), 'Making value: Craft in changing times', Cultural Trends, 20: 3-4, pp. 309-316.

Zaman, H., Özkar, M. and Çagdas, G. (2011), 'Towards hands-on computing in design: An analysis of the haptic dimension of model making', Metu Journal of the Faculty of Architecture, 28: 2, pp. 209-226.

Zequn, M. and Rui, G. (2010), 'The direction of footwear computer-aided design in China', in Proceedings of Computer-Aided Industrial Design and Conceptual Design (CAIDCD), IEEE 11th International Conference, pp. 222-225, China, Yiwu: IEEE.

\section{Author Biographies}

\section{Jenny Pinski}

Jenny Pinski is a Lecturer in Textiles at Loughborough University, she is leader of the woven textiles pathway and member of the Textile Design Research Group. Her research interests revolve around hands-on, craft-based approaches to design and the application of textile approaches in other disciplines. In particular, she is interested in the potential for this to support design innovation and sustainable practice. She uses her experience as a practitioner to engage in practice-led research and is interested in the role of design practice in academic research.

\section{Faith Kane}


Faith Kane is a design researcher and educator working in the area of textiles and materials. Her research interests include: design for sustainability; interdisciplinary and transdisciplinary working in the design/science space; and the role and value of craft knowledge within these contexts. She is a Senior Lecturer and Programme Coordinator for Textiles at the School of Design, College of Creative Arts at Massey University in Wellington, New Zealand and is also a founder editor of the Journal of Textile Design Research and Practice, published by Routledge Taylor Francis. More information about her work can be found at www.faithkane.com.

\section{Mark Evans}

Mark Evans is a Reader in Industrial Design and Leader of the Design Practice Research Group. Designed research outputs have been exhibited at the National Centre for Craft and Design/London Design Festival; recognised through the International Design Excellence Awards/Impact Case Study for REF2014; promoted by the Industrial Designers Society of America (IDSA)/German Design Council/Design Denmark. He has supervised/examined 26 $\mathrm{PhDs}$, with external appointments as AHRC/British Council reviewer; visiting professor at Rhode Island School of Design; editorial board member for The Design Journal; International Scholar at MIT. In 2016 he received the IDSA Educator of the Year Award.

\section{Corresponding Author Contact:}

Jenny Pinski

Post: Loughborough University School of the Arts, Epinal Way, Loughborough, LE11 3TU. Email: J.Pinski@lboro.ac.uk

Tel: +44(0)1509228998

\section{List of Figures}

1. Analysis map of the design process data, (C) Jenny Pinski.

2. Categories and definitions used for data analysis, (C) Jenny Pinski.

3. Illustrated diagram of the design process, methods and approaches used in the case study, (C) Jenny Pinski.

4. Radar diagram showing the frequency of codes applied in the 3D non-digital activities used at the in-depth research stage and whether they informed the final designs, (C) Jenny Pinski.

5. An example of $2 \mathrm{D} / 3 \mathrm{D}$ approaches to idea generation involving sketching and quick modeling techniques, (C) Jenny Pinski.

6. Technical specification for setting up the loom generated using a 2D digital approach, (C) Jenny Pinski.

7. Radar diagram showing the frequency of codes applied in the 3D non-digital activities used at the design development stage and whether they informed the final designs, (C) Jenny Pinski.

8. Design presentation sheet generated using 2D/3D hybrid approaches, C Jenny Pinski.

9. Proposed integrated design process workflow with the key roles of hands-on exploration with materials at each stage, (C) Jenny Pinski. 